\title{
An Overview of Quantum Information Science Courses at US Institutions
}

\author{
Bianca Cervantes and Gina Passante \\ Physics Department, California State University, Fullerton, 800 N State College Blvd, Fullerton, CA, 92831 \\ Bethany Wilcox and Steven Pollock \\ Department of Physics, University of Colorado, Boulder, Boulder, Colorado, 80309, USA
}

As the field of Quantum Information Science (QIS) continues to advance, there is an increased need for a quantum-smart workforce to address the needs of the growing quantum industry. As institutions begin to expand their course offerings, there is a unique opportunity for discipline-based education researchers to have an impact on the curricular and pedagogical choices being made in these courses. As a first step, it is necessary for education researchers to have a representative picture of what QIS education currently looks like. We reviewed recent course catalogues from a large sample of institutions in the United States looking for courses focused on QIS content. Our conservative analysis reveals that roughly a quarter of the institutions we reviewed offer QIS courses. While encouraging for such an emerging field, we found disparities in the types of institutions offering these courses as the vast majority were Doctoral-granting institutions. Additionally, we found that some classifications of minority serving institutions were much less likely to offer a QIS course (for example Historically Black Colleges and Universities or Predominantly Black Institutions), while Asian American and Native American Pacific Islander serving institutions were more likely than the national average to offer a QIS course. These disparities may lead to further racial, socioeconomic, and geographic disparity in the future quantum workforce. We also found that there was no single department that offered a majority of the QIS courses, indicating that the best efforts to improve QIS education will need to consider the multi-disciplinary nature of the field of quantum information science.

2021 PERC Proceedings edited by Bennett, Frank, and Vieyra; Peer-reviewed, doi.org/10.1119/perc.2021.pr.Cervantes Published by the American Association of Physics Teachers under a Creative Commons Attribution 4.0 license. Further distribution must maintain the cover page and attribution to the article's authors. 


\section{INTRODUCTION}

Quantum information science (QIS) is the catch-all term used to describe the rapidly growing field related to quantum computing, quantum sensing, and quantum communication. The development of a quantum computer, for example, would revolutionize the way many computations are performed, from unordered searches to factoring large numbers. In recent years, the United States government has committed to supporting QIS by passing the National Quantum Initiative Act [1] in December of 2018, which outlines a plan to ensure the United States emerges as a leader of QIS in both academia and industry. Part of this plan involves the creation of Quantum Leap Challenge Institutes [2] that will play a key role in the education of future leaders in this field. The National Strategic Overview for Quantum Information Science [3] identifies the need for a quantum-smart workforce to address growing industry, academic, and government needs. It is quickly becoming clear that fulfilling these needs will not be limited to $\mathrm{PhD}$ level scientists, but will require skilled technicians at the Masters and Bachelor degree levels from a variety of disciplines [4].

In response to these efforts, there has been a growing number of proposed QIS programs throughout the country, both at the graduate and undergraduate level [5]. There are also some national efforts to organize resources for QIS instruction [6] and to bring educators together [7-10]; however, most educators creating courses and programs are undertaking parallel efforts with the goal of bringing QIS education to a broader audience. As these new educational efforts are still in their infancy, there is a unique opportunity for discipline-based education researchers (DBER) to have an impact on the educational decisions being made to ensure these programs are effective and equitable.

One of the challenges facing QIS education and related DBER efforts is the multidisciplinary nature of QIS. Physics is not the only field represented in QIS research and education as computer science, electrical and computer engineering, mathematics, and chemistry also play a major role. In order to effectively understand how DBER can best contribute to educational efforts supporting QIS, we need to better understand what courses currently exist as well as where, and by whom, they are being taught. Many of the efforts to create QIS programs are being designed to broaden access to this field, yet, it remains unclear who these courses are serving. Are they mostly at the graduate or undergraduate level? Are these courses and programs spread across all institutions or mostly at research-intensive doctoral institutions? The goal of this work is to answer these questions and create a picture of the current state of QIS education in the United States as well as to provide a useful, up-to-date database for researchers, educators, and program managers. This work will provide a much needed snapshot of the status of this emerging field that can be used to guide both educational researchers and QIS program developers.

\section{RESEARCH METHODOLOGY}

We began our search by using the American Institute of Physics roster of physics departments with enrollment numbers [11]. The roster has a total of 767 departments located in the United States. We prioritized our search by sorting institutions by their Fall 2019 senior enrollments, with the goal of searching the largest institutions first. We prioritized the larger departments for two reasons: we felt these departments were the most likely to have specialized courses outside the physics core curriculum, and these departments represent a large fraction of the overall population of physics students. The research team then searched the online course catalogues of each institution for any courses related to QIS based on our criteria described below.

This process of identifying courses involved locating the online course catalogues for both undergraduate and graduate programs for each institution. The 2019-2020 course catalogs were the primary sources. (If not found, we searched for a 2020-2021 catalog). In cases where no course cata$\log$ could be found for the institution as a whole, individual college and department websites were searched, focusing on physics, computer science, engineering, and mathematics departments. The course search consisted of two phases. In the first phase, an undergraduate researcher searched each institution's course catalogue for the term 'quantum'. They then read the course descriptions for each course associated with the word quantum and made a decision as to whether or not it should be included in the list. The inclusion criteria were that the course had to have a substantial focus on QIS topics (indicated by at least half of the material being QIS related). We excluded courses where QIS was listed as a potential 'application' topic or a 'time permitting' topic as these are unlikely to meet the criteria for having at least half of the course focused on QIS. We also excluded laboratory-only courses from our analysis as these are unlikely to have detailed instruction on QIS theory. Finally, special topics courses were excluded due to the non-standard way they may (or may not) appear in a course catalogue, therefore including them would have likely lead to discrepancies in that some special topics courses would be found and others would not. The first phase of course selections was designed to be inclusive; ambiguous cases where it was not immediately clear whether the course met the criteria were retained at this stage and scrutinized in the second phase. For each course found we recorded the course name and number, the offering department, the institution, the educational level of the course (graduate or undergraduate), a link to the course catalogue, and any instructor information if available.

In the second phase of this search, two researchers with QIS-specific education and/or research experience reviewed the list of course names that were included after the first phase. Any course name that was clearly related to QIS was included. Examples include courses with the titles "Introduction to Quantum Computation" and "Quantum Information Systems". Any course name that was less obvious was re- 
TABLE I. Carnegie Classifications for to classify each of the institutions in our data set.

\begin{tabular}{ll}
\hline \hline Institution type & Carnegie Classifications Included \\
\hline Doctoral & Very High Research Activity (DVH), \\
& High Research Activity (DH), and \\
& Doctoral/Professional Universities (DP) \\
& Larger Programs (ML), \\
Master's & Medium Programs (MM), and \\
& Small Programs (MS) \\
& Arts and Sciences Focus (BAS), \\
Baccalaureate & Diverse Fields (BDF), and \\
& Special Focus: Engineering Schools (SFE) \\
\hline \hline
\end{tabular}

searched in further detail and the course description was located. Courses that included QIS as a major component of the course were included. This was the case for a course entitled "Novel Computing Technologies" from a Computer Science department. The course description states: "Novel computing technologies that could revolutionize computer architecture. Quantum computing technologies, including algorithms, devices, and fault tolerance. A survey of other unconventional technologies including nanoscale electronics, MEMS devices, biological devices, and nanotechnology." [12] It was clear from the description and topic list that QIS constitutes at least half of the course and therefore it was included in our list. An example of a course that did not meet the criteria was entitled "Applied Cryptography" with the description of "key management, hash functions, stream ciphers, Web of trust, time stamping, secret sharing, quantum cryptography, running time analysis, cryptanalytic techniques" [13]. As quantum cryptography was only one in a larger list of topics, and clearly constituted less than half of the course content, this course was eliminated at this stage.

A total of 305 institutions were searched (which represents $40 \%$ of the total institutions on the AIP roster). In practice it was not possible to search the entire list, nor did we feel it was necessary. These 305 institutions represent $83 \%$ of the Fall 2019 Senior Enrollments, 75\% of 2019 Physics Bachelor recipients, and $89 \%$ of 2019-awarded Physics PhDs [14]. Our list of courses is not a complete list, however that was not the goal. By sampling a large percentage of the institutions covering the majority of student enrollments, we are able to create a representative picture of what QIS instruction looks like throughout the USA at this date. We are not looking to make statistical claims, but rather look at trends that will allow QIS Education researchers to better understand the current educational landscape of this emerging field.

Once the course search was complete, the type of institution was recorded using the Carnegie Classification of Institutes of Higher Education [15]; the particular classifications used are given in Table I. We simplified the Carnegie classifications by categorizing schools as either doctoral institutions, masters institutions, or baccalaureate institutions. Descrip-
TABLE II. List of MSI Designations. Note that no NANTI or TCU institution was in the 305 institutions surveyed, and the only MSI institutions that offered QIS courses were AANAPI and HSI.

\begin{tabular}{ll}
\hline \hline MSI Code & Description \\
\hline ANNH & Alaska Native and Native Hawaiian \\
AANAPI & Asian American and Native American Pacific Islander \\
HSI & Hispanic-Serving Institutions \\
HBCU & Historically Black Colleges and Universities \\
PBI & Predominantly Black Institutions \\
NANTI & Native American-Serving Non-Tribal Institutions \\
TCU & Tribal College or University \\
\hline \hline
\end{tabular}

tions of each of these categories can be found at Ref. [15]. We also recorded whether the school was classified as public or private using the same Carnegie database. All private institutions included in the search were not for profit.

Additionally, we noted whether or not institutions on our list were minority serving institutions (MSI's). An MSI is an institution which receives federal funding under Part $F$ of the Higher Education Act, entitled "Investment in historically Black colleges and universities and other minority-serving institutions," for serving a specific, significant population of minority students [16]. To determine an institution's MSI status, we used NASA's Minority Serving Institutions Exchange database [17]. The MSI categories recorded in our database are given in Table II. Note that institutions sometimes carry more than one MSI designation. An institution that has at least one MSI designation was considered a Minority Serving Institution.

\section{RESULTS}

We reviewed the public catalogs of 305 institutions and found that $74(24 \%)$ of these institutions had courses related to QIS in their course catalogues. At these 74 institutions there were a total of 123 courses; 46 (37\%) of these courses were undergraduate only, $62(50 \%)$ were graduate only, and $15(12 \%)$ were listed as joint undergraduate/graduate courses.

When looking at the departments that offered these 123 courses, 58 (47\%) of these courses were either offered by or cross-listed with a physics department (Phys). There were $27(22 \%)$ courses offered (or cross-listed) in electrical and/or computer engineering departments (ECE), 34 (28\%) in computer science and/or information departments (CS), 6 (5\%) courses in mathematics departments, 4 (3\%) in QIS specific departments, and 5 in other departments (not cross-listed with any previously reported). All 4 courses in a QIS department were from the same institution. A breakdown of the levels of courses offered by each department can be found in Table III.

We were also interested in the types of institutions offering courses. To determine this, we used the Carnegie Classifications of Institutions of Higher Education (as seen in Table I). 


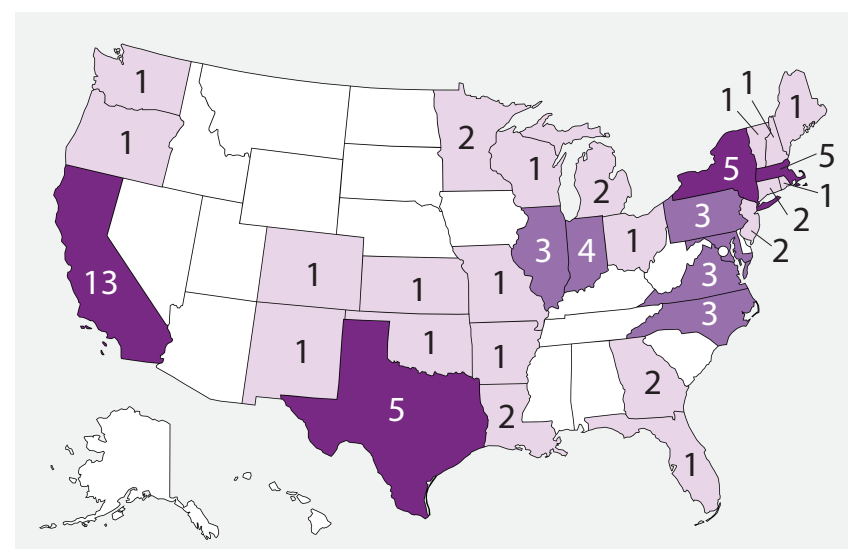

FIG. 1. A map indicating the number of institutions, in each state, offering QIS courses. States colored white without a number have zero institutions offering QIS courses. No US territories have institutions identified by our search criteria with QIS courses, and are not pictured here.

In our full sample of 305 institutions, 193 (63\%) are classified as doctoral institutions, $64(21 \%)$ as masters colleges and universities, and $48(16 \%)$ as baccalaureate institutions. Of the 74 institutions that offer a QIS course, $64(86 \%)$ are classified as doctoral institutions, $5(7 \%)$ as masters colleges and universities, and $5(7 \%)$ as baccalaureate institutions. If we take a closer look at the 64 doctoral institutions which offer QIS courses, we find 38 of them (or 59\%) offer courses at the undergraduate level.

We also considered where within the United States the majority of QIS courses are being offered. The results can be found in Figure 1. One is much more likely to find a QIS course at an institution located along the perimeter of the USA, rather than the interior. Our sample included institutions from 46 states (states not included are North Dakota, South Dakota, Mississippi, and Arkansas) and one territory (Puerto Rico). We found 29 states (and no territories) had at least one institution offering at least one QIS course.

In addition to the Carnegie Classifications, we looked at whether or not each institution surveyed had an MSI designation. Of the 305 surveyed institutions, 56 (18\%) were listed as MSIs. Of those 56 MSIs, 15 (27\%) offer one or more QIS course. This result indicates that MSI's might be

TABLE III. Course levels separated by department. Note that each rows does not add to the total in the far right column because some courses are cross-listed across multiple departments.

\begin{tabular}{l|cccccc|c}
\hline \hline & Phys & ECE & CS & Math & QIS & Other & Total \\
\hline Undergraduate & 22 & 8 & 15 & 2 & 0 & 3 & 46 \\
UG/Graduate & 7 & 4 & 5 & 0 & 0 & 1 & 15 \\
Graduate & 29 & 15 & 14 & 4 & 4 & 2 & 62 \\
\hline Total & 58 & 27 & 34 & 6 & 4 & 6 & 123 \\
\hline \hline
\end{tabular}

TABLE IV. Percent of institutions surveyed and the distribution of QIS courses (at any level) by Carnegie classification.

\begin{tabular}{l|cc}
\hline \hline $\begin{array}{l}\text { Institution } \\
\text { type }\end{array}$ & $\begin{array}{c}\text { \% Inst. Surveyed } \\
(N)\end{array}$ & $\begin{array}{c}\text { \% Inst. with } \\
\text { QIS courses }(N)\end{array}$ \\
\hline Doctoral & $63 \%(193)$ & $86 \%(64)$ \\
Master's & $21 \%(64)$ & $7 \%(5)$ \\
Baccalaureate & $16 \%(48)$ & $7 \%(5)$ \\
\hline \hline
\end{tabular}

TABLE V. Percent of institutions offering courses by MSI designation.

\begin{tabular}{l|ccc}
\hline \hline $\begin{array}{l}\text { Institution } \\
\text { MSI Designation }\end{array}$ & $\begin{array}{c}\text { Institutions } \\
\text { surveyed }\end{array}$ & $\begin{array}{c}\text { Institutions with } \\
\text { QIS courses }\end{array}$ & with courses \\
\hline non-MSI & 249 & 59 & $24 \%$ \\
AANAPI & 9 & 5 & $56 \%$ \\
HSI & 24 & 5 & $21 \%$ \\
AANAPI \& HSI & 18 & 5 & $28 \%$ \\
Other MSI & 5 & 0 & $0 \%$ \\
\hline All institutions & 305 & 74 & $24 \%$ \\
\hline \hline
\end{tabular}

slightly more likely to offer QIS courses than the full sample of institutions. However, when we break down the MSI institutions by designation, we see that not all MSI institutions offer courses equally. Of the seven MSI designations used in the NASA MSI Exchange database, there were only two types of designations that included QIS courses: AANAPI (Asian American and Native American Pacific Islander Serving Institutions) and HSI (Hispanic-Serving Institutions). In our sample, there were 9 AANAPI institutions, 24 HSI, and 18 that carried both the AANAPI and HSI designations. The number and percentage of these institutions offering QIS courses is found in Table V. We find great disparity in the fraction of each of these types of institutions that offer QIS courses. In our sample, AANAPI institutions offered QIS courses at a higher rate than any other institution type, including both non-MSI and Hispanic-serving institutions. Perhaps most importantly, no other MSI offered a QIS course; however, it is important to note that only 5 institutions with other MSI designations were sampled.

We lastly considered whether an institution was publicly or privately funded. There were almost twice as many public in-

TABLE VI. Comparing QIS courses offered at public and private institutions.

\begin{tabular}{l|cccc}
\hline \hline & $\begin{array}{c}\text { Inst. } \\
\text { surveyed }\end{array}$ & $\begin{array}{c}\text { Inst. with } \\
\text { QIS courses }\end{array}$ & $\begin{array}{c}\text { \% Inst. with } \\
\text { QIS courses }\end{array}$ & $\begin{array}{c}\% \text { of those with } \\
\text { UG courses }\end{array}$ \\
\hline Public & 198 & 46 & $23 \%$ & $52 \%$ \\
Private & 107 & 28 & $26 \%$ & $79 \%$ \\
\hline All & 305 & 74 & $24 \%$ & $62 \%$ \\
\hline \hline
\end{tabular}


stitutions as private institutions in our sample, with both types offering QIS courses at fairly similar rates $(23 \%$ for public and $26 \%$ for private). However, if we look at the undergraduate courses offered by these institutions, we find that private institutions are much more likely to offer undergraduate QIS courses $(79 \%$ for private compared to $52 \%$ for public institutions). These data can be found in Table VI.

\section{DISCUSSION}

In this work, we looked at the QIS course offerings in a significant sampling of institutions across the United States at this time. Of the institutions surveyed, 24\% offered QIS courses as found by their course catalogues. This is an underestimate, as we found several instances of special topics courses or reading courses on QIS that were not included in this list.

We found that, of the 74 institutions that offer courses on QIS, 65 (88\%) are doctoral granting institutions; however, only 54\% of physics Bachelor's degree graduates come from these institutions. Of the Bachelor degrees in Physics awarded in $2018,40 \%$ were awarded from institutions whose highest degree offering is a Bachelors [18]. However, of the 47 Baccalaureate institutions sampled, 5 (11\%) offered QIS courses. At the current time, students at baccalaureate institutions are much less likely to have access to a QIS course. When looking at the jobs available in the QIS industry, Fox et al. report that more than half of the companies with QIS divisions surveyed have at least one employee, with at most, a Bachelor's degree (in either engineering, physics, or computer science) [4]. As QIS companies grow and QIS technologies continue to evolve, it is expected that the number of positions available that only require a Bachelor's degree will increase [5]. This suggests that Bachelor's only programs should not be neglected in the development of quality QIS education.

There is a lot of discussion about broadening access to the QIS field [6]. In some ways, that is being accomplished as more and more institutions are offering QIS courses. However, the distribution of courses is not uniform among across all institution types. As stated above, Doctoral degree granting institutions are much more likely to offer courses. Additionally, the student body makeup of institutions offering courses does not accurately reflect that of the country as a whole. We found QIS courses at institutions that held MSI designations of AANAPI and HSI, yet none at any other minority serving institutions. AANAPI serving institutions seem, at this time, much more likely to offer QIS courses than either HSI institutions or the sample as a whole. We also found there to be a disparity in the likelihood of offering undergraduate QIS courses between private and public institutions, with private institutions much more likely to offer undergraduate courses. These disparities, along with the fact that QIS courses are not offered at institutions in all states, indicate a lack of uniform access to QIS education across the
United States. This lack of access is a concern both from an equity and inclusion standpoint, which potentially limits the growing QIS field from accessing the full diversity of talented new scientists.

This study has a number of limitations. In addition to not sampling all institutions in the United States, we were unable to include all instances of QIS education being offered at this time. For example, students may learn elements of QIS from courses which were not included in our database such as special topics courses and courses that included QIS as a small component of the material. This exclusion may also have an impact on our findings regarding the types of institutions offering QIS courses, as institutions with more resources are more likely to develop new programs and courses beyond special topics courses. Indeed, it is likely more costeffective and timely to incorporate QIS instruction into preexisting courses or offer a special topics course, particularly for smaller schools. Additionally, course catalogue descriptions often lag behind modifications to course content, therefore our search may have missed additional courses. Finally, we recognize that this is a time of large growth in the field of QIS education and many institutions are in the process of introducing courses and programs into their curriculum, that which may not have been included in the 2019-2020 course catalogues we sampled.

In order for discipline-based education researchers to have an impact on QIS education, it is important to know which departments are offering courses. Less than half of the courses found were offered or cross-listed with Physics departments, although there were more courses found in physics departments than any other department. Both electrical and computer engineering (ECE) and computer science departments (CS) offered a large number of QIS courses. The best efforts to improve QIS education will consider the multi-disciplinary nature of the field of quantum information science, given that experts in Physics Education Research are unlikely to also be experts in Engineering Education Research (for example), and will likely benefit from cross-department collaborations.

Given the relatively young age of quantum information science as a field, we were excited to find that almost a quarter of institutions surveyed currently offer QIS courses, especially as we recognize that this is likely an under-estimate. However, while this news is encouraging for broadening access to this exciting emerging field, we found disparities in the types of institutions offering these courses, which may lead to further racial, socioeconomic, and geographic disparity in the future quantum workforce.

\section{ACKNOWLEDGMENTS}

This work has been supported in part by the NSF under Grants No. PHY-2011958 and No. PHY-2012147. The authors would like to thank Josephine Meyer for her assistance in Phase 2 of the search for QIS courses. 
[1] "Text - H.R.6227 - 115th Congress (2017-2018): National Quantum Initiative Act I Congress.gov I Library of Congress." [Online]. https://www.congress.gov/bill/115th-congress/ house-bill/6227/text. Retrieved 11/21/2019.

[2] "Quantum Leap Challenge Institutes (QLCI) I NSF - National Science Foundation." [Online]. https://www.nsf.gov/ pubs/2019/nsf19559/nsf19559.htm. Retrieved 06/25/2019.

[3] Subcommittee on quantum information science, "National strategic overview for quantum information science," Executive office of the President of the United states, Sep. 2018.

[4] Michael F. J. Fox, Benjamin M. Zwickl, and H. J. Lewandowski, Phys. Rev. Phys. Educ. Res. 16, 020131 (2020).

[5] Clarice D. Aiello et al 2021 Quantum Sci. Technol. in press https://doi.org/10.1088/2058-9565/abfa64

[6] National K-12 Education Partnership: Growing the Quantum Workforce https://q12education.org/ Retrieved 6/2/2021.

[7] Kavli Futures Symposium: Achieving a Quantum Smart Workforce https://quantum-workforce.kavlimeetings.org/ Retrieved $6 / 2 / 2021$

[8] Open Quantum Frontier Institute Virtual Workshop: Quantum Education https://sites.google.com/sjsu.edu/ oqfi-quantumeducation/home?authuser=0 Retrieved 6/2/2021.

[9] NSF Workshop on Quantum Engineering Education https://www.osa.org/en-us/meetings/topical_meetings/ quantum_engineering_education_workshop/_ Retrieved $6 / 2 / 2021$

[10] Quantum Undergraduate Education Scientific Training
Workshop https://www.csusm.edu/quest/index.html Retrieved $6 / 2 / 2021$.

[11] Roster of Physics Departments with Enrollment and Degree Data, 2019 https://www.aip.org/statistics/reports/ roster-physics-2019. Retrieved 10/13/2020.

[12] Course ECS 203: Novel Computing Technologies https://cs.ucdavis.edu/schedules-classes/ ecs-203-novel-computing-technologies Retrieved 5/26/2021.

[13] Course CS 181: Applied Cryptography https://www.scu.edu/ bulletin/undergraduate/2019-2020-Undergraduate-Bulletin. pdf Retrieved 6/2/2021.

[14] These numbers were calculated using the numbers reported in the AIP roster, and there were 66 institutions that did not provide data to the AIP, therefore their numbers are not included here

[15] The Carnegie Classification of Institutions of Higher Education https://carnegieclassifications.iu.edu/ Retrieved 5/10/2021.

[16] Lists of post-secondary institutions enrolling populations with significant percentages of undergraduate minority students, https://www2.ed.gov/about/offices/list/ocr/edlite-minorityinst. html Retrieved 5/23/2021.

[17] NASA List of Minority Serving Institutions https://www.nasa.gov/sites/default/files/atoms/files/ 2020-nasa-list-of-minority-serving-institutions.pdf Retrieved 5/24/2021.

[18] Physics Bachelor's Degrees: 2018 https://www.aip.org/ statistics/reports/physics-bachelors-degrees-2018 Retrieved 5/28/2021. 